\title{
The Spatial Analysis of Monastery on the Qinghai-Tibet Plateau
}

\author{
Zhuoma CAIJI ${ }^{a}$, Luo GUO ${ }^{b}$ Dayuan XUE ${ }^{c}$,Yuhuan DU ${ }^{d}$
}

\author{
College of Life and Environmental Sciences, Minzu University of China, Beijng, China \\ acaijizhuomaht@126.com, 'buoluo2010@163.com, ‘xuedayuan@hotmail.com, \\ dyuhuan0306@hotmail.com
}

\section{Keywords:Monastery; GIS; Spatial Analysis}

\begin{abstract}
The spatial analysis of Tibetan Buddhist monastery is an underrepresented area of research on ecological environment in China. In this article, we use the 1987, 1997, 2007 remote sensing data, DEM and field survey material, and research on the characteristics of spatial distribution of 66 monasteries at Guo Luo Tibetan Autonomous Prefecture located in QingHai-Tibet plateau. And we analyze the differences of land use types and landscape pattern between monastery and settlement in $4 \mathrm{~km}$ area. The results show that the monasteries mainly distribute in altitude between 4000 4500 m, and most monasteries of Guo Luo are located in steeper slope gradient and gentle slope gradient. Compared with the change of land use type of settlement, the change of land use type and landscape pattern of monastery is more stable than that of settlement.
\end{abstract}

\section{Introduction}

Qinghai-Tibet Plateau, known as "the roof of the world" and "the third polar of the earth", is not only the climatic regulator of China and even the world, but also the "river source" and "ecological source" of China and the South Asian region. Due to the unique physical features such as permafrost, lakes, wetlands and the original plateau surface constituting of hills, a comprehensive yet special ecological system is formed in this region ${ }^{[1,2]}$.

The unique ecological environment also fosters rich culture in various ethnic groups, including Tibetan people, Mongolian people, Hui people, and so on. As the majority in this region, Tibetan culture, especially religion culture, is considered as the representative culture of high plateau. Tibetan Buddhism, the dominant religion for all Tibetan people, has guided people to respect the natural environment and look for a balance between human beings and the natural environment. A key belief in Tibetan Buddhism culture is the fear and worship for monasteries,sacred lakes, sacred mountains, and sacred forest. It gradually forms ecological culture and indirectly teaches Tibetan people to have better ecological consciousness, ecological concept, living behavior and awareness of the biological and cultural diversity ${ }^{[3]}$. In many cultures of the world, the belief of sacred natural sites is important for environmental conservation. The respect of the environment and restrictions to access sacred sites has often led to well-conserved areas with high biological diversity ${ }^{[4]}$. There have many researches on the sacred sites around the world, such as Mongolian Sacred Sites ${ }^{[5]}$, Japan's Sacred Mountains ${ }^{[6]}$, Adam' s Peak Sacred Mountain Forest ${ }^{[7]}$ and so on, which proved the religious constraints and taboos play an important role in protection of ecological environment of monastery. In China, Xiang et al ${ }^{[8]}$ the studied sacred mountain and result showed that the texture and characteristics of soil of sacred mountain were significant better than that of ordinary mountain. Within the sampling plots,all the study indexes of sacred mountain were better than the ordinary mountain,the number of plant species in sacred mountain and ordinary mountain were 47 and 36 
respectively,the Simpson index were 0.585 and 0.533 respectively, the Shanon-Wiener index were 0.4775 and 0.4482 respectively, the Pielou index were 0.3544 and 0.327 respectively. Salick ${ }^{[9]}$ investigated Kagebo mountain and surrounding villages, the research found that breast diameter of tree and canopy density of forest in the Kagebo mountain significantly greater than in ordinary mountain area. In many faith traditions, location holds both functional and theological significance, and neighborhood worship-houses are associated with sacred spaces ${ }^{[10]}$.

Conventionally, monasteries have been mapped as a community asset, as they are popularly perceived to exemplify the best forms of social capital ${ }^{[11]}$. The Christian ministry Global Mapping International, for instance, uses the Global Ministry Mapping System in Arcview software to calculate the ratio of churches and population in each neighborhood and to explore spatial relationship between population and religious culture ${ }^{[12]}$. Tibetan Buddhist monastery represents the continuation of Tibetan Buddhism culture. They factor heavily in the daily religious functions of many people. The monastery serves as not only a place for worshiping nature and god, but also as a demonstration site of environmental preservation. It is important to figure out the spatial distribution and social functions of monasteries in China. Geographic information system (GIS) offers a powerful set of tools for analyzing spatial data ${ }^{[11]}$. Thus, the aim of this paper is to applying GIS to the spatial analysis of monasteries on the Qinghai-Tibet Plateau to analyze the spatial distribution and land use change of monastery and discuss what the role of monastery play in the local ecological environment.

\section{Study area and methods}

Study area

Guo Luo Tibetan Autonomous Prefecture is located in the hinterland of the QingHai-Tibet plateau $\left(97{ }^{\circ} 54^{\prime}-121^{\circ} 50 ' \mathrm{E}, 32^{\circ} 31^{\prime}-35^{\circ} 40 \prime \mathrm{N}\right)$, covers about $76955 \mathrm{~km} 2$. Located in the southeast of Qinghai province, this place serves as the source of the Yellow River, and is one of six Tibetan Autonomous Prefecture in QingHai. Tibetan people take up 91.24\% of the total population of 149500. Tibetan Buddhism is the religion of $99 \%$ of this region's population and 66 monasteries are distributed amongst its six counties, including Maqin, Maduo, Dari, Gande, Jiuzhi, Banma .

Method

Spatial data such as elevation, slope are extracted from DEM (1:250,000) based on the ArcGIS software. Two variables: elevation and slope. Based on the analysis of land-use data obtained through the TM/ETM images in the years of 1987, 1997 and 2007 in the study area and combined with a 1:250 000 scale topographic map and thematic maps for soil and vegetation of the study area, buy using GIS software, this paper obtains the character of land-use change (Fig.1). An object-based image classification analysis method is used in this study. Then, the distribution information of monasteries got from GIS positioning and field survey material are added on the land-use map of Guo Luo. Under the environment of the extension module of "Spatial Analyst" in the ArcGIS software, buffer zones with radiuses of $4 \mathrm{~km}$ and monastery and settlement as centers are established to analyze the surrounding eco-environment of monastery and settlement.

\section{Results}

The spatial distribution of monasteries in Guo Luo Tibetan Autonomous Prefecture

On the basis of the topographic characteristics of Guo Luo, this region is divided eight levels: $0 \sim$ $1000 \mathrm{~m}, 2500 \sim 3000 \mathrm{~m}, 3000 \sim 3500 \mathrm{~m}, 3500 \sim 4000 \mathrm{~m}, 4000 \sim 4500 \mathrm{~m}, 4500 \sim 5000 \mathrm{~m}, 5000 \sim$ $5500 \mathrm{~m},>5500 \mathrm{~m}$. Distribution of monasteries in different altitudes are shown in Table 1 by 
applying ArcGIS software. The monasteries mainly distribute in altitude between 3 500 4 $500 \mathrm{~m}$. $21.07 \%$ of them distributed altitude range from $4500 \sim 5000 \mathrm{~m}$. Only 5 monasteries are located above $5000 \mathrm{~m}$. There are no monastery in altitude above $5000 \mathrm{~m}$. Therefore, the altitude $5000 \mathrm{~m}$ can be regarded as the highest altitude distribution of Guo Luo Prefecture monasteries (Fig.2).

According to the data on slope gradient, the distribution density of monastery increases with the slope gradient increased (Table.1). This result shows that most monasteries of Guo Luo prefecture are located in steeper slope gradient $\left(15^{\circ}-25^{\circ}\right)$.

Table.1 Relationship between slope gradient and monastery distribution in Guo Luo Prefecture

\begin{tabular}{ccccccc}
\hline $\begin{array}{c}\text { Slope } \\
\text { gradient }\end{array}$ & $\begin{array}{c}\mathrm{NP} \\
(\mathrm{n})\end{array}$ & $\begin{array}{c}\text { Total Area } \\
\left(\mathrm{km}^{2}\right)\end{array}$ & $\begin{array}{c}\text { Area } \\
\text { Proportion } \\
(\%)\end{array}$ & $\begin{array}{c}\text { Number of } \\
\text { monastery } \\
(\mathrm{n})\end{array}$ & $\begin{array}{c}\text { Monastery } \\
\text { Proportion } \\
(\%)\end{array}$ & $\begin{array}{c}\text { Density of } \\
\text { monastery } \\
\left(\mathrm{n} / \mathrm{km}^{2}\right)\end{array}$ \\
\hline $0-7$ & 13076970 & 30811.5 & 40.04 & 5 & 7.58 & 0.0002 \\
$7-15$ & 2506992 & 20306.6 & 26.39 & 18 & 27.27 & 0.0009 \\
$15-25$ & 2185542 & 17702.9 & 23.00 & 34 & 51.52 & 0.0019 \\
$>25$ & 1004228 & 8134.25 & 10.57 & 9 & 13.64 & 0.0011 \\
Total & & 76955.2 & 100 & 66 & 100 & \\
\hline
\end{tabular}
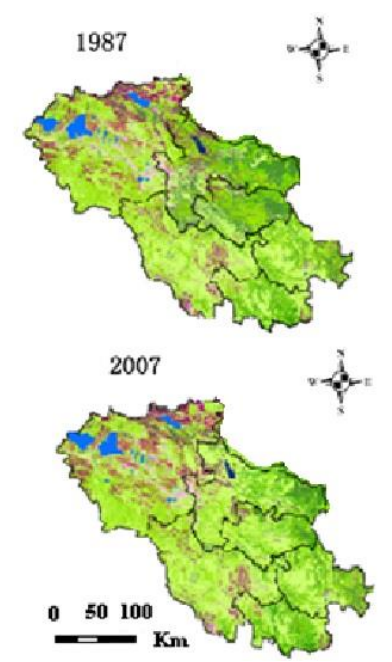

Fig 1. Land cover classification of Guo Luo

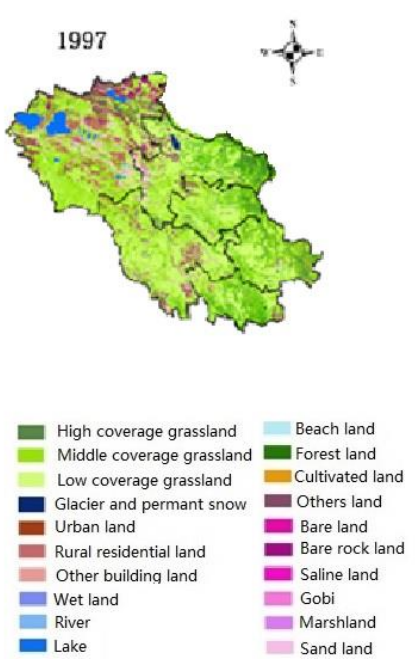

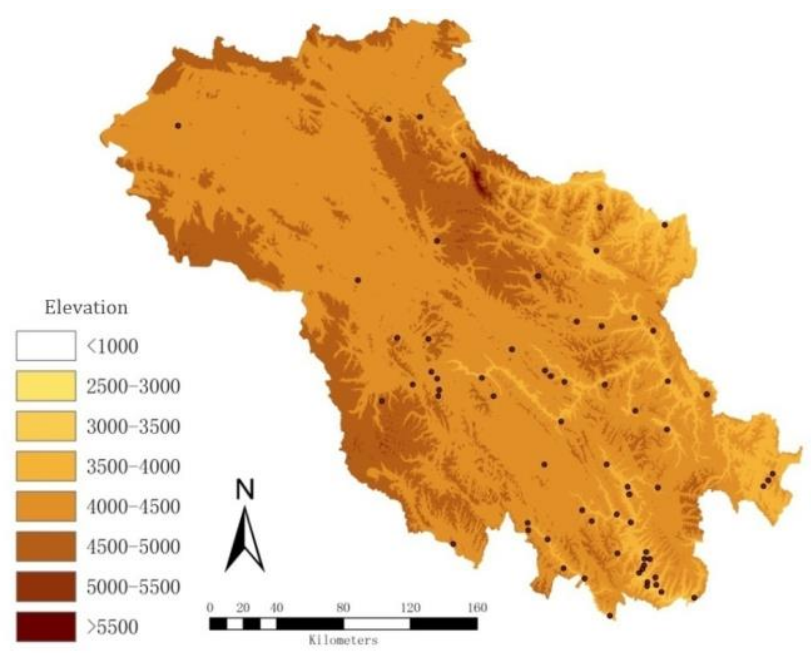

Fig 2. Spatial distribution of monastery in Guo Luo

The spatial change of land use of monastery and settlement in Guo Luo

Change of land use of monastery and settlement

Based on the data of 1987, 1997 and 2007 landsat TM/ETM imageries, we observe the spatial change of land use of monastery and settlement in $4 \mathrm{~km}$ buffer area. The results we got include the following content: $30 \%$ of land cover type of settlements exhibit varying degrees of land degeneration, however, $12 \%$ of land cover type of monasteries show varying degrees of land degeneration. This result indicates that the land cover type of the surrounding monasteries is more stable than that of the settlements. Additionally, the degeneration ratio of land cover type of settlements near road is higher than that of the settlements near monastery and the settlements near Yellow river. Meanwhile, land cover type of the settlements near scared lake has no change. In a word, the change of land use of surrounding monastery, river and lake is better than that of surrounding settlement.

Change of landscape index of monastery and settlement

Analyzing landscape index of monasteries and settlements in $4 \mathrm{~km}$ buffer area (Table 2 and Table 3), we obtained these results: First, mean patch size of monastery is bigger than that of settlement in 
$4 \mathrm{~km}$ buffer area. Therefore, in same landscape level, landscape of settlement is more vulnerable than that of monastery. In addition, the number of patch and fragmentation index of monastery is significantly lower than that of settlement within the $4 \mathrm{~km}$ buffer from 1987 to 2007 . Sum up to above results, surrounding environment of monastery is more stable and superior than that of ordinary residential area.

Table 2 Changes of landscape index of monastery in $4 \mathrm{~km} 1987$ to 2007

\begin{tabular}{ccccc}
\hline Years & $\begin{array}{c}\mathrm{CA} \\
\left(\mathrm{hm}^{2}\right)\end{array}$ & $\begin{array}{c}\text { NP } \\
(\mathrm{n})\end{array}$ & $\begin{array}{c}\text { MPS } \\
\left(\mathrm{hm}^{2}\right)\end{array}$ & FN \\
\hline 1987 & 300330.15 & 1457 & 206.12 & 0.00485 \\
1997 & 300330.15 & 1480 & 202.92 & 0.00492 \\
2007 & 300330.15 & 1461 & 200.66 & 0.00486 \\
\hline
\end{tabular}

Table 3 Changes of landscape index of settlement in $4 \mathrm{~km} 1987$ to 2007

\begin{tabular}{ccccc}
\hline Years & $\begin{array}{c}\text { CA } \\
\left(\mathrm{hm}^{2}\right)\end{array}$ & $\begin{array}{c}\text { NP } \\
(\mathrm{n})\end{array}$ & $\begin{array}{c}\text { MPS } \\
\left(\mathrm{hm}^{2}\right)\end{array}$ & FN \\
\hline 1987 & 331394.34 & 2536 & 130.68 & 0.00765 \\
1997 & 331394.34 & 2525 & 131.24 & 0.00762 \\
2007 & 331394.34 & 2524 & 131.29 & 0.00762 \\
\hline
\end{tabular}

\section{Summary}

This paper adopts GIS to attempt to understand the nature of monastery on the Qinghai-Tibet Plateau and their interactions with the surrounding ecological environment. From this article we can know that the change of land use type and landscape pattern of monastery is more stable than that of settlement, and fragmentation index of monastery is significantly lower than that of settlement within the $4 \mathrm{~km}$ buffer from 1987 to 2007. In addition, landscape pattern of surrounding river and lake is better than that of surrounding settlement. There have some reasons for these results we got. Firstly, geographic distribution characteristics of the monastery impact itself environment, but most of monasteries are located near the settlements. Secondly, Tibetan traditional ecological idea deeply influence on the local people, both the monastery and local people voluntarily protect the surrounding ecological environment of monastery. Which is main reason why the monastery surrounding environment is superior and more stable than other locations. Traditional ecological knowledge and culture help Tibetan people have better understanding of effective governance and protection of sacred places, and take positive effects on local eco-environmental conservation. Monastery has always been a center piece in Tibetan culture and as such, plays an important role in the research of the culture and environment surrounding it. Therefore, we think that the monastery can be regarded as a link with local and our government to effectively propaganda and strengthen consciousness of people for environmental protection. Finally, we will do more researches on traditional cultural attractions use a multidisciplinary approach to elaborate the influence of traditional culture on the human survival environment.

\section{Acknowledgement}

The work presented in this paper was supported by the National Natural Science Foundation of China (No. 31370480) and 111 Project (B08044). We also acknowledge all people who help us built the library. 


\section{Reference}

[1] X.D. Wang, X.H. Zhong, S.Z. Liu, et al. Regional assessment of environmental vulnerability in the Tibetan plateau: Development and application of a new method, Journal of Arid Environments. 72(2008)1929-1939.

[2]G.D. Cheng and T.H. Wu. Responses of permafrost to climate change and their environmental significance, Qinghai-Tibet Plateau, Journal of Geophysical Research. 112 (2007).

[3]L.Y. Hong, B. LIU, J.Q. LI, et al. Ecological implication and signification of holy mountains in Tibetan area, northwest Yunnan,China, Jouranal of MUC (Natural Scicence Editon). 22 (2013)77-78.

[4]T. Schaaf. UNESCO's experience with the protection of sacred natural sites for biodiversity conservation, The Importance of Sacred Natural Sites for Biodiversity Conservation. (2003)13-20.

[5]N. Urtnasan. Mongolian sacred sites and biodiversity conservation, The Importance of Sacred Natural Sites for Biodiversity Conservation. (2003)91-100.

[6]K. Iwatsuki. Japan's sacred mountains, The Importance of Sacred Natural Sites for Biodiversity Conservation. (2003) 89-90.

[7]A.Wickramasinghe. Adam's peak sacred mountain forest, The Importance of Sacred Natural Sites for Biodiversity Conservation. (2003)108-117.

[8]H.M. Xiang, J.F. Zhang, H.M. Xu, et al. Vegetation comparison of Tibetan holy mountain and ordinary mountian in Shangri-la county, Journal of West China Forestry Science. 37 (2008)47-50.

[9]S. Jan, A. Anthony, A. Danica, et al. Tibetan sacred sites conserve old growth trees and cover in the eastern Himalayas, Biodiversity and Conservation. 16 (2007)693-706.

[10]P.H. Cheong, P. H. Poon, S. Huang. The internet highway and Religious communities:mapping and contesting spaces in religion-online, The Information Society. 25(2009)291-302.

[11]A. Combera, C. Brunsdona, E. Green. Using a GIS-based network analysis to determine urban greenspace accessibility for different ethnic and religious groups, Landscape and Urban Planning. 86 (2008)103-114.

[12]P.D. Robert. Bowling alone: The collapse and revival of American community(ed). Simon and Schuster, New York, 2001. 